\title{
UM BREVE BALANÇO DA POESIA DE AUGUSTO DE CAMPOS - 80 ANOS DE VIDA DO AUTOR
}

\author{
Mayra Berto MASSUDA ${ }^{45}$
}

Quinta edição da "Balada Literária" (São Paulo, 20 de novembro de 2010) - Conversa informal com o poeta Augusto de CAMPOS, conduzida pelo Prof. Dr. Ivan Marques (USP) e transcrita por Mayra Berto Massuda (UNESP/Araraquara) especialmente para a revista eletrônica TextoPoético.

A "Balada Literária", evento que acontece anualmente na cidade de São Paulo, reúne críticos aclamados, escritores reconhecidos e desconhecidos, uma imensa variedade de músicos e atores, e um público muito participativo e atualizado. A quinta edição, realizada em novembro de 2010, homenageou a escritora Lygia Fagundes Telles, e dentre as várias vozes reunidas sob a organização do poeta pernambucano Marcelino Freire, estava a do professor da USP Ivan Marques, em um descontraído bate-papo com o poeta Augusto de Campos.

Augusto, hoje octogenário, expôs de forma muito esclarecedora pontos ainda obscuros e polêmicos da sua poesia, rememorou os primórdios da Poesia Concreta, comentou o difícil e enriquecedor trabalho de traduzir e também a ferrenha crítica que sua poesia sofreu e tem sofrido. No final, apresentou-se com a banda de seu filho, o músico Cid Campos. Uma performance memorável e histórica, do modesto poeta que duvidava de sua capacidade em manter o fôlego, seja na oralização, seja na escritura de poesia, deixando em suspense o que ainda está por vir na edição da "Balada Literária" de 2011, na qual será homenageado.

Conforme apresentado por Ivan Marques, Augusto de Campos, "poeta, tradutor e ensaísta, crítico de literatura e música, um dos fundadores do Movimento da Poesia Concreta, ao lado de Haroldo de Campos e Décio Pignatari" ${ }^{46}$, é um poeta de grande concisão e radicalidade. A coerência de sua obra, principalmente no período histórico da Poesia Concreta, na verdade havia se configurado desde seu primeiro livro, O rei

\footnotetext{
${ }^{45}$ Graduanda pesquisadora de IC (Bolsa FAPESP), Departamento de Literatura, Faculdade de Ciências e Letras, Universidade Estadual Paulista, UNESP, campus de Araraquara, CEP 14800-901, Araraquara, SP, Brasil - massuda_mayra@ hotmail.com

${ }^{46}$ Todas as citações são parte da documentação sonora do evento, transcrito pela autora.
} 
menos o reino (1951), no qual já se nota indícios do small eye-ear-poet com o qual Augusto se autodefine.

Em 1948, quando seu primeiro poema foi publicado em um jornal da época, Augusto enfrentou a oposição de críticos renomados, como Sérgio Buarque de Holanda, Antonio Candido e Sérgio Milliet da Costa e Silva, de quem o poeta - bem-humorado afirma não guardar ressentimentos: "Eu preferia os inimigos de ontem, não é? Eles escreviam tão bem. Eu acho aquilo delicado até”.

Também em 1948, Augusto de Campos conheceu Décio Pignatari em uma mesa redonda no Instituto dos Arquitetos, na qual se apresentava o poeta Murilo Mendes. O inicial estranhamento com o poema "O Lobisomem", de Décio, estreitou o contato entre os poetas, que se estendeu para discussões semanais de poesia.

Em 1952, Augusto, Haroldo e Décio têm contato com o Grupo Ruptura e seus principais artistas plásticos, Waldemar Cordeiro e Luís Sacilotto, que já se denominavam concretistas por fazerem obras plásticas que se opunham ao abstracionismo e ao "hedonismo pictórico", aproximando-se de uma arte geométrica.

A partir da articulação dos artistas plásticos e dos poetas paulistas com outros artistas e poetas do Rio de Janeiro, o Concretismo é oficialmente fundado em 1956 na Exposição Nacional de Arte Concreta no MAM (São Paulo). No contexto literário em que o movimento nascia, declarava uma espécie de insurgência à “Geração de 1945", que segundo Augusto de Campos, "tendia mais para uma coisa mais conservadora, voltar ao soneto, voltar às rimas. E não era o que a gente achava que deveria ser feito na época”.

Em sua fala, Augusto ainda cita referências artísticas pelas quais se interessava na época, como os filmes de Eisenstein, das vanguardas do início do século (como o expressionismo alemão), as obras de Picasso e os móbiles de Alexander Calder da primeira Bienal de São Paulo (1951), a música de Schoenberg, Webern e John Cage, a arquitetura de Oscar Niemeyer, a filosofia de Heidegger e Sartre, e a poesia de Ungaretti, Montale, Rilke e Iessiênin: "Isso tudo a gente assimilava. E achava que tudo parecia com a poesia que a gente estava fazendo".

Todo esse repertório contribuiu para um brainstorm, no qual os poetas mergulharam e do qual selecionaram o mais relevante para a configuração do movimento. Para Augusto de Campos, essa era uma visão já de Oswald de Andrade, de 
“antropofagia virtual", e não "antropofagia por fome". O que posteriormente culminou na criação de um paideuma de poetas que serviria de referência para a Poesia Concreta: Ezra Pound, Mallarmé, e. e. cummings e James Joyce.

Desse modo, em sua obra poética, na qual se inclui também as traduções, é possível notar indícios de um leitor detalhista e crítico desses grandes escritores da modernidade e alguns pouco compreendidos como o brasileiro Sousândrade, demonstrando seu forte caráter agregador, muito mais construtivo do que destruidor. Que tendia mais a resgatar os grandes poetas inventores do que romper com qualquer resquício de tradição: "Nossa posição era de procurar a invenção do passado."

No bate-papo, de forma muito interessante, Ivan Marques lembra a insistência da crítica quanto a sua rotulação como poeta da recusa, da angústia, do menos, do antilirismo e do "não". Para ilustrar, o professor cita - brilhantemente - "o primeiro verso do primeiro poema do primeiro livro" de Augusto: "Onde a Angústia roendo um não de pedra" ${ }^{47}$.

Ao fazer uma espécie de mea culpa, o poeta afirma que até se arrepende um pouco de ter usado tanto o "não", já que alguns críticos, muitas vezes esquecem os poemas ao enfatizar apenas o título. Na verdade, para ele, a primeira ideia era marcar uma oposição à poesia vigente, se desidentificar com a produção contemporânea se desfazendo do poema e do título de poeta: “Quer dizer, não tenho nada com isso, então não sou poeta. O que sou é outra coisa, que não sei definir. Talvez eu seja mais um designer do que poeta, mais um músico do que designer. Eu não sei."

De fato, Augusto de Campos tem poemas líricos, como os da série Poetamenos (1953), endereçados à Lygia Azeredo de Campos (na época namorada e atual esposa). E a sua recusa - à palavra, ao figurativismo e ao lirismo - se dá sistematicamente apenas na "fase ortodoxa" da Poesia Concreta (1956-1961), quando houve

[...] um esforço violento de contensão. Até para fazer com que fôssemos entendidos, a gente tinha que radicalizar. Sem radicalizar, você não faz revolução nenhuma. Não vira a mesa. Você fica lá, in media res, naquela situação média que não leva a nada, o que o [Waldemar] Cordeiro chamava de 'meia de nylon tamanho único'.

\footnotetext{
${ }^{47}$ CAMPOS, Augusto. O rei menos o reino. In:
} Viva vaia: poesia 1949-1979. São Paulo: Ateliê Editorial, 2000. p.9. 
Se, para Ivan Marques, há temas recorrentes desde o início da produção de Augusto, como a angústia, a melancolia, a morte e o silêncio, o poeta lembra que foi principalmente em seus poemas a partir da década de 1970 que o subjetivismo, que Carlos Ávila chama de “construtivismo lírico", veio à tona. Despoesia (1994), por exemplo, é um livro com muitos poemas metafísicos. E até mesmo o poema “cidade/ciy/cité", que foi escrito em 1963, já demonstrava a contensão dando lugar à liberdade e extravasamento, principalmente semântico, do poema.

$\mathrm{Na}$ contramão do que a crítica mais superficial e estreita suspeitava, em sua obra, Augusto de Campos não tenta "matar a poesia", ou então, fazer apologia à negação e destruição, seja da palavra, do lirismo ou do passado. Para o poeta, esse "não" recorrente, talvez tenha sido apenas incentivado pela marginalidade da poesia no meio cultural e literário, uma espécie de "gueto" artístico "à margem da margem" 48.

Quando questionado sobre a relação do poema "pós-tudo" (1984), com a poesia "pós-moderna" ou "pós-utópica", Augusto afirma não acreditar, nem compreender muito bem o que seria o "pós-moderno" em termos de poesia. O poema põe em questão esse conceito que surgiu muito apropriadamente no âmbito da arquitetura, mas que quando aplicado à literatura - e à poesia - está muito mais ligado a uma repetição do moderno ou a um "retro-moderno" - "uma volta, uma desculpa quase, para voltar a uma poesia mais conservadora".

Diante do vazio e da ambiguidade do que seria "pós-moderno", Augusto constrói um poema autoirônico, no qual propõe uma situação de mudança e ao mesmo tempo de emudecimento. Casualmente, o título aproximou-se do termo "pós-utópico", do artigo de Haroldo de Campos ${ }^{49}$, do qual Augusto não tinha conhecimento prévio. Ambos provocaram várias críticas e polêmicas que, segundo o próprio poeta, acabaram por favorecer a divulgação do poema.

Tão importante quanto seus poemas de própria autoria, seu extenso trabalho de tradução - que vai dos provençais à poesia russa moderna - faz parte da identidade artística do poeta. Para Augusto de Campos, a tradução também é um trabalho de criação, pois os poemas são refeitos em termos artísticos.

\footnotetext{
${ }^{48}$ Expressão criada por Décio Pignatari e citada por Augusto de Campos também em obra: CAMPOS, Augusto de. À margem da margem. São Paulo: Companhia das Letras, 1989.

${ }_{49} \mathrm{O}$ artigo ao qual Augusto de Campos se refere encontra-se em: CAMPOS, Haroldo de. Poesia e modernidade: da morte da arte à constelação. O poema pós-utópico. In: ensaios de literatura e cultura. Rio de Janeiro: Imago, 1997. p.243-269. 
O que o irmão, Haroldo, chamou de "transcriação", Augusto chama de “tradução-arte", em analogia ao "futebol-arte" brasileiro:

A nossa ideia era não fazer traduções literais, aquelas traduções que não se preocupam com o ritmo, com a sonoridade, com as características materiais do poema. Nós queríamos recriar os poemas. De certa maneira, rivalizar um pouco com os poemas, embora sabendo que, raros casos, nós chegaríamos a ter o mesmo valor que os poetas que nós traduzíamos e que admirávamos muito.

Não que a tradução literal não tenha seu valor, o próprio poeta reconhece a grande valia da tradução literal do provençal antigo. Entretanto, como poeta e como artista, uma tradução que não levasse em consideração a materialidade - visual e sonora - da palavra, entraria em desacordo com seus princípios artísticos e estéticos.

Essa essência artística de Augusto de Campos está longe de ser restrita à identidade de "poeta concreto" ou "poeta concretista", a qual ele refuta e deseja manterse afastado hoje: "Nós não somos poetas concretos. Nós somos poetas." Sendo que a sua obra poética - seja ela em versos, visual, digital ou de tradução - demonstra uma grande variedade de temas, formas, materiais e técnicas, além de uma primorosa habilidade na experimentação com a linguagem.

Entre a polêmica provocada, principalmente no meio acadêmico, na segunda metade do século passado, e as novas leituras e aproximações que tanto a Internet, como o leitor mais receptivo alcançaram, é necessário o equilíbrio de uma crítica que, como Augusto de Campos, não despreze o passado na compreensão do novo e que enxergue na radicalidade utópica da vanguarda, uma necessidade momentânea para sair da mesmice da falta de "invenção".

Diante da heterogeneidade de sua poesia - e da poesia contemporânea em geral - uma crítica que encontra saídas fáceis ao renegar a experimentação tende apenas a limitar a compreensão de certas obras e a favorecer a publicidade de outras duvidosas. No fim de tudo, como bem sinaliza o poeta: "Cada um tem o poeta que merece."

\section{REFERÊNCIAS}

CAMPOS, A. de. Viva vaia: poesia 1949-1979. São Paulo: Ateliê Editorial, 2000. À margem da margem. São Paulo: Companhia das Letras, 1989. 
CAMPOS, H. de. Poesia e modernidade: da morte da arte à constelação. O poema pósutópico. In:__ O arco-íris branco: ensaios de literatura e cultura. Rio de Janeiro: Imago, 1997. p.243-269. 